Supporting Information

\title{
Synthesis of Perovskite CsPbBr 3 Quantum Dots/Porous Boron Nitride Nanofiber Composites with Improved Stability and Their Reversible Optical Response to Ammonia
}

Xin He, ${ }^{\dagger, \S}$ Chao Yu, ${ }^{\dagger, \S}$ Mengmeng Yu, ${ }^{\dagger}, \S$ Jing Lin, ${ }^{*}, \dagger, \S$ Qiaoling Li, ${ }^{\dagger, \S}$ Yi Fang, ${ }^{\dagger}, \S$ Zhenya Liu, ${ }^{\dagger, \S}$ Yanming Xue, ${ }^{\dagger, \S}$ Yang Huang, ${ }^{*},+, \S$ and Chengchun Tang*, ${ }^{*, \$}$

$\dagger$ School of Materials Science and Engineering, Hebei University of Technology, Tianjin 300130, P. R. China

$\S$ Hebei Key Laboratory of Boron Nitride Micro and Nano Materials, Hebei University of Technology, Tianjin 300130, P. R. China

Corresponding Author

*E-mail: linjing@hebut.edu.cn (J. Lin), huangyang@hebut.edu.cn (Y. Huang), tangcc@hebut.edu.cn (C. Tang) 


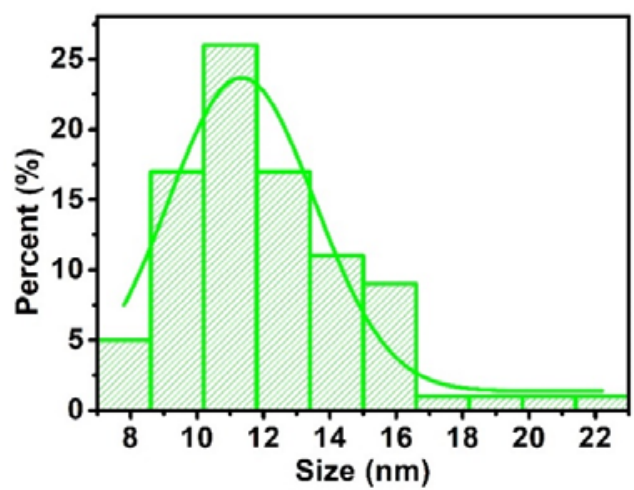

Figure S1 Size distribution of the loaded $\mathrm{CsPbBr}_{3}$ QDs.

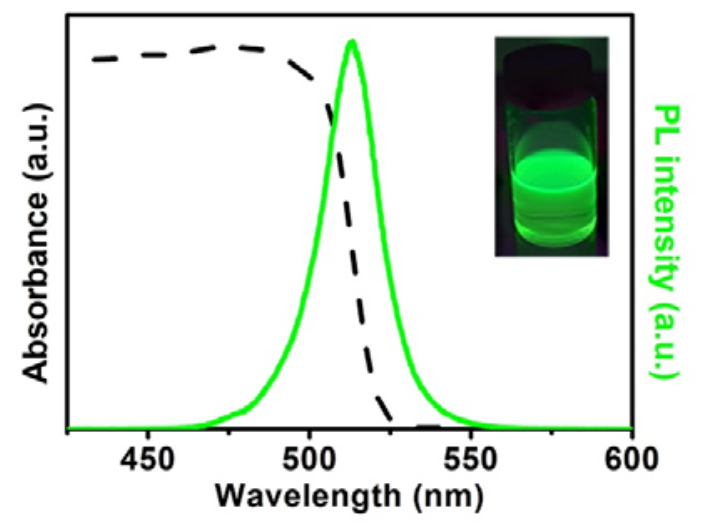

Figure S2 Absorption (dashed lines) and PL (solid lines) spectra of $\mathrm{CsPbBr}_{3}$ QDs $\left(\lambda_{\mathrm{exc}}=365 \mathrm{~nm}\right)$. The insets are photographs of $\mathrm{CsPbBr}_{3}$ QDs solution under UV light (365 nm) irradiation.

From the PL emission and UV-vis absorption spectra of $\mathrm{CsPbBr}_{3}$ QDs (Figure S2), an absorption peak at $492 \mathrm{~nm}$ is observed and the corresponding PL emission peak is located at 511 $\mathrm{nm}$. The bright green emission could be observed upon $365 \mathrm{~nm}$ UV illumination (inset in Figure $\mathrm{S} 2)$. The absolute PLQY of the $\mathrm{CsPBBr}_{3}$ QDs is measured to be $\sim 60 \%$. 


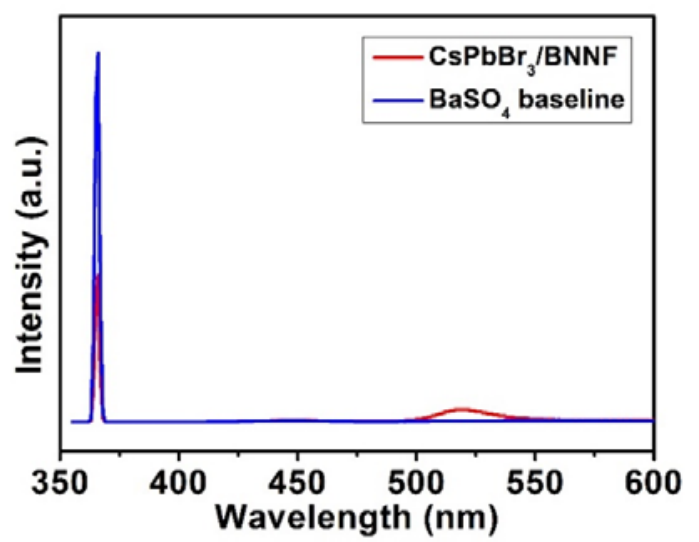

Figure S3 PLQY measurement of $\mathrm{CsPbBr}_{3} / \mathrm{BNNF}$ composites.

\begin{tabular}{|c|c|c|c|c|c|}
\hline Sample & $\mathrm{T}_{1}(\mathrm{~ns})$ & $\mathrm{A}_{1}(\%)$ & $\mathrm{T}_{2}(\mathrm{~ns})$ & $\mathrm{A}_{2}(\%)$ & $\mathrm{T}_{\text {avg }}(\mathrm{ns})$ \\
\hline $\mathrm{CsPbBr}_{3}$ & 6.579 & 45 & 22.685 & 55 & 10.796 \\
\hline $\mathrm{CsPbBr}_{3} / \mathrm{BNNF}$ & 6.707 & 21 & 34.215 & 79 & 18.477 \\
\hline
\end{tabular}

Table S1. The PL decay curves of the $\mathrm{CsPbBr}_{3}$ QDs and $\mathrm{CsPbBr}_{3} / \mathrm{BNNF}$ composites can be described by two-exponential fitting: $I(t)=A+B_{1} * \exp -i / T_{1}+B_{2} * \exp -i / T_{2}$.

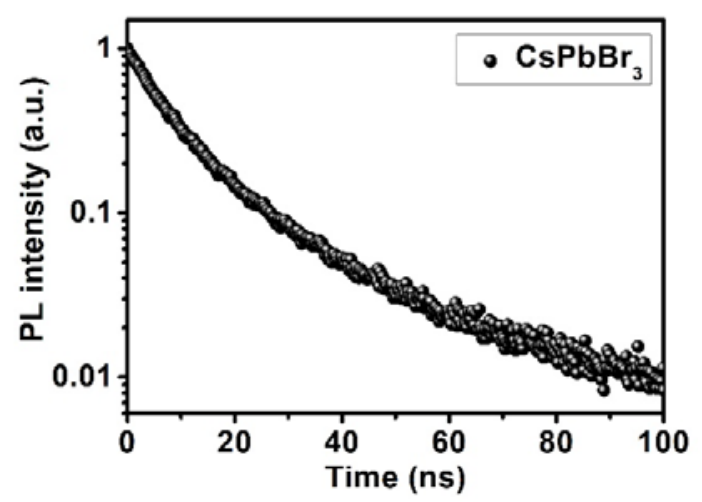

Figure S4 Time-resolved PL decay curve for the $\mathrm{CsPbBr}_{3}$ QDs.

The PL decay curve of the $\mathrm{CsPbBr}_{3}$ QDs is shown in Figure S4. The curve can be well fitted with a two-exponential decay function (Table S1). The average lifetime of $\mathrm{CsPbBr}_{3} \mathrm{QDs}$ is $\sim 10.796$ ns. The short-lived PL lifetime is 6.579 ns with a percentage of $45 \%$ and a long-lived process is 22.685 ns with a percentage of $55 \%$. 

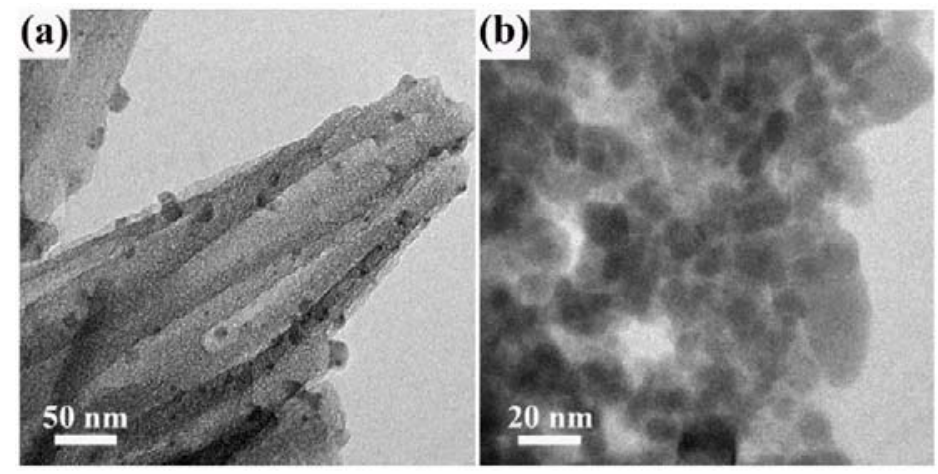

Figure S5 TEM images of the $\mathrm{CsPBr}_{3} / \mathrm{BNNF}$ composite powders (a) and $\mathrm{CsPbBr}_{3}$ QDs solution (b) after UV illumination for $96 \mathrm{~h}$.

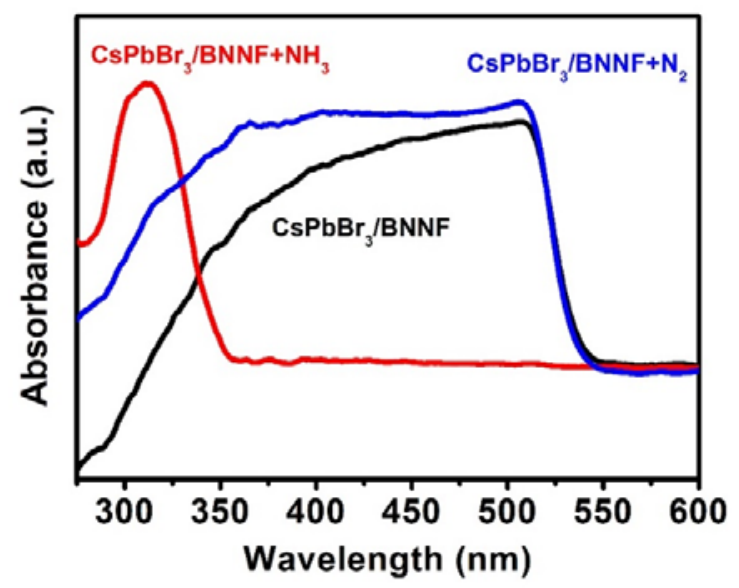

Figure S6 UV-vis absorption spectra of $\mathrm{CsPbBr}_{3} / \mathrm{BNNF}$ composite powders in the presence of $\mathrm{NH}_{3}$ $\left(\mathrm{CsPbBr} / \mathrm{BNNF}+\mathrm{NH}_{3}\right)$ and $\mathrm{N}_{2}\left(\mathrm{CsPbBr}_{3} / \mathrm{BNNF}+\mathrm{N}_{2}\right)$. 


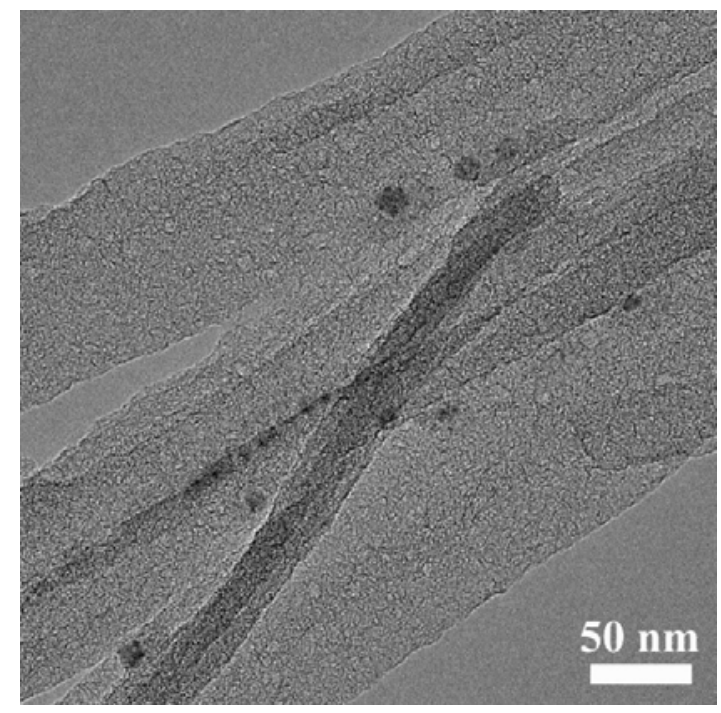

Figure S7 TEM images of $\mathrm{CsPbBr} 3 / \mathrm{BNNF}$ composites after four repeated cycles of $\mathrm{NH}_{3} / \mathrm{N}_{2}$ treatment.

(a)
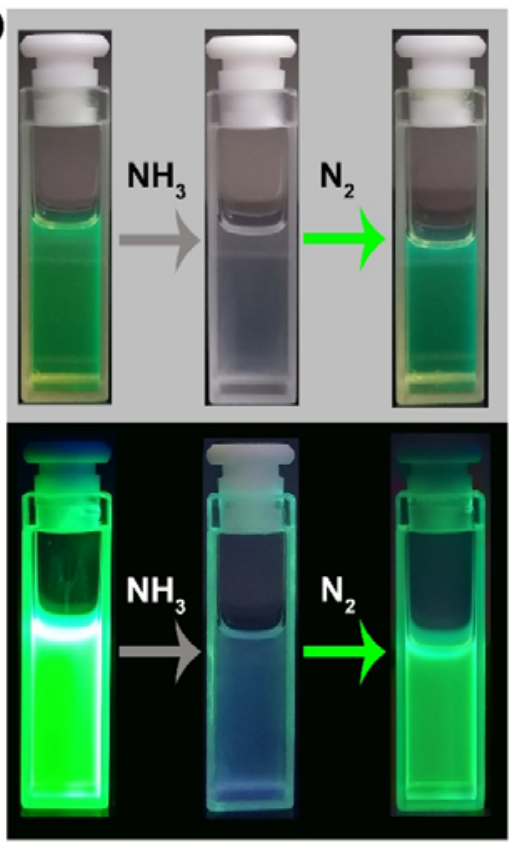

(b)

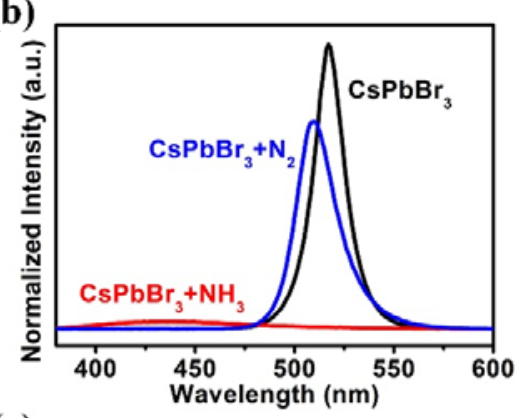

(c)

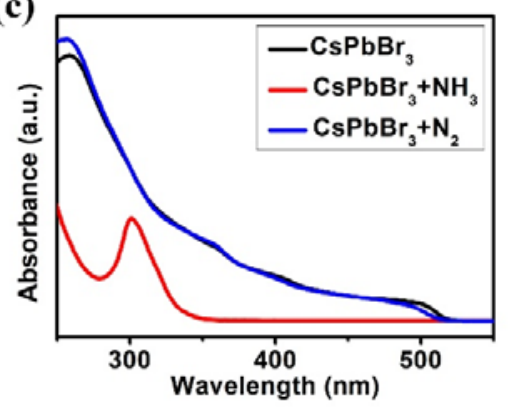

Figure S8 (a) The color changes of $\mathrm{CsPbBr}_{3}$ QDs solution after exposure in $\mathrm{NH}_{3} / \mathrm{N}_{2}$ gas. (b, c) Emission spectra and UV-vis absorption of $\mathrm{CsPbBr}_{3}$ QDs solution in the presence of $\mathrm{NH}_{3}$ $\left(\mathrm{CsPbr}_{3}+\mathrm{NH}_{3}\right)$ and $\mathrm{N}_{2}\left(\mathrm{CsPbBr}_{3}+\mathrm{N}_{2}\right)$. 
(a)

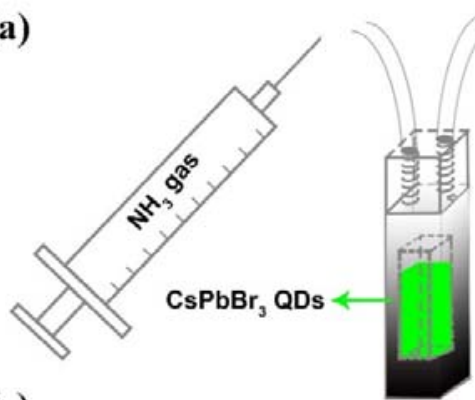

(c)

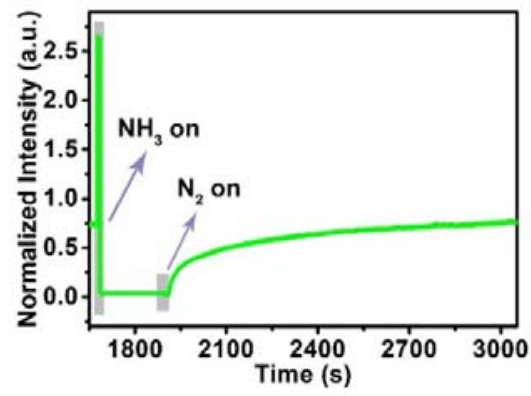

(b)

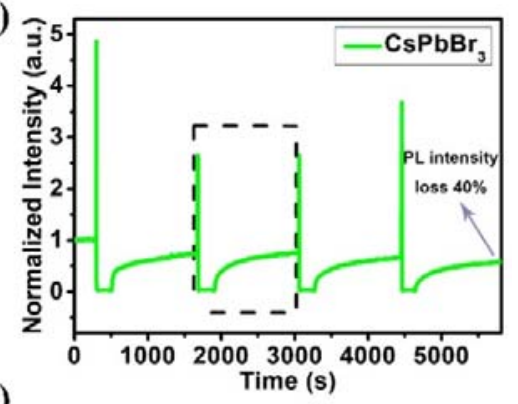

(d)

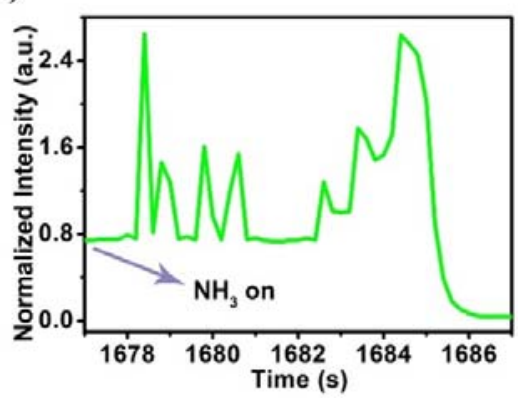

Figure S9 (a) Schematic of a quartz fluorescent flow cuvette for testing the $\mathrm{NH}_{3}$ responsive behavior of $\mathrm{CsPbBr} 3$ solution. $0.3 \mathrm{~mL}$ of the sample (the amount of $\mathrm{CsPbBr}_{3} \mathrm{QDs}$ is estimated to be $\sim 1.5 \mathrm{mg}$ ) was added to the flow cuvette and monitor the change in the PL intensity of the sample. During the test, pure $5 \mathrm{~mL} \mathrm{NH}_{3}$ or $\mathrm{N}_{2}$ were injected into the cuvette through an external tube. (b) Reversibility test under alternating injection of $\mathrm{NH}_{3}$ gas or $\mathrm{N}_{2}$ gas. (c) The enlarged portion of the black rectangle in Figure b. (d) The change in instantaneous PL intensity of $\mathrm{NH}_{3}$ gas injection.

In order to clarify the mechanism of $\mathrm{NH}_{3}$-induced changes in the PL properties of $\mathrm{CsPbBr}_{3} / \mathrm{BNNF}$ composites, similar $\mathrm{NH}_{3}$-treatment test was performed on pure $\mathrm{CsPbBr}_{3}$ QDs solution sample. The $\mathrm{CsPbBr}_{3}$ QDs solution exhibits similar color and PL intensity change to the composite powders in the presence of $\mathrm{NH}_{3} / \mathrm{N}_{2}$ gas (Figure S8a and S8b). Figure S8c compares the absorption spectrum of the $\mathrm{Cs} \mathrm{PbBr}_{3}$ QDs solution after introduction of $\mathrm{NH}_{3}$ gas $\left(\mathrm{CsPBr}_{3}+\mathrm{NH}_{3}\right)$. Unlike pure $\mathrm{CsPbBr}_{3}$ QDs solution, the absorption spectrum of the white solution disappears in the visible region and a new absorption peak appears at $302 \mathrm{~nm}$.

We used another quartz fluorescence flow cuvette (shown in Figure $\mathrm{S} 9$ a) to inject $\mathrm{NH}_{3}$ gas or $\mathrm{N}_{2}$ gas and the kinetics curve is shown in Figure S9b. The PL intensity increases immediately after the introduction of $\mathrm{NH}_{3}$ gas, and then decreases to $\sim 4 \%$ of the original intensity; when exposure to 
$\mathrm{N}_{2}$ gas, the PL intensity of the QDs gradually recovers. Nevertheless, the PL intensity of the solution decreased by $40 \%$ after four repeated cycles. Figure S9c is an enlarged portion of the black rectangular frame in Figure S9b, and Figure S9d is an instant re-amplification of the $\mathrm{NH}_{3}$ gas treatment. In the presence of $\mathrm{NH}_{3}$ gas, $90 \%$ of the $\mathrm{PL}$ intensity quenching degree is achieved within $9 \mathrm{~s}$. When $\mathrm{N}_{2}$ gas is introduced, the PL intensity can be restored to $90 \%$ of the highest intensity of the cycle within $12 \mathrm{~min}$.

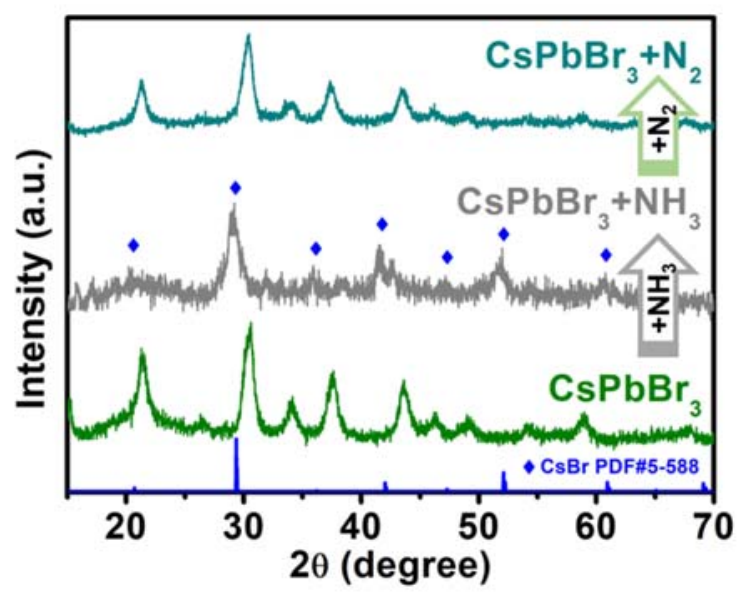

Figure S10 XRD patterns of the CsPbBr 3 QDs before and after being exposed to the $\mathrm{NH}_{3}$ and $\mathrm{N}_{2}$ atmosphere.

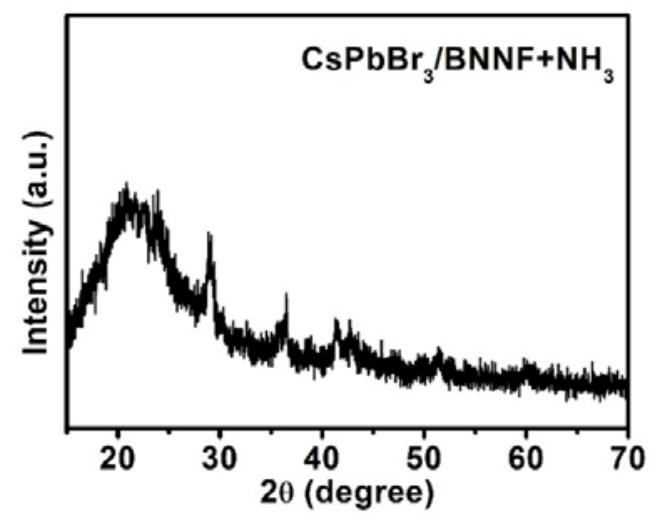

Figure S11 XRD patterns of the $\mathrm{CsPbBr} 3 / \mathrm{BNNF}$ composites after being exposed to the $\mathrm{NH}_{3}$ atmosphere.

XRD pattern of $\mathrm{CsPbBr}_{3}$ QDs changes substantially after exposed to $\mathrm{NH}_{3}$ gas. The white crystal can be indexed as cubic CsBr phase (JCPDS card No. 5-588). After treated with $\mathrm{N}_{2}$, the 
product changed back to $\mathrm{CsPBr}_{3}$ phase. We consider this to be the result of a proton exchange reaction between the $\mathrm{Cs}^{+}$and adsorbed ammonia in the QDs (eq 1). There are excess $\mathrm{Br}^{-}$on the surface of the QDs, ${ }^{1}$ and the $\mathrm{Cs}^{+}$are substituted and combined with $\mathrm{Br}^{-}$to form $\mathrm{CsBr}$ (Figure $\mathrm{S} 12$ ).

$$
2 \mathrm{CsPbBr}_{3}+\mathrm{NH}_{3}+\mathrm{Br}^{-}+\mathrm{H}^{+} \rightleftharpoons 2 \mathrm{CsBr}+\left(\mathrm{NH}_{4}\right)\left(\mathrm{Pb}_{2} \mathrm{Br}_{5}\right)
$$
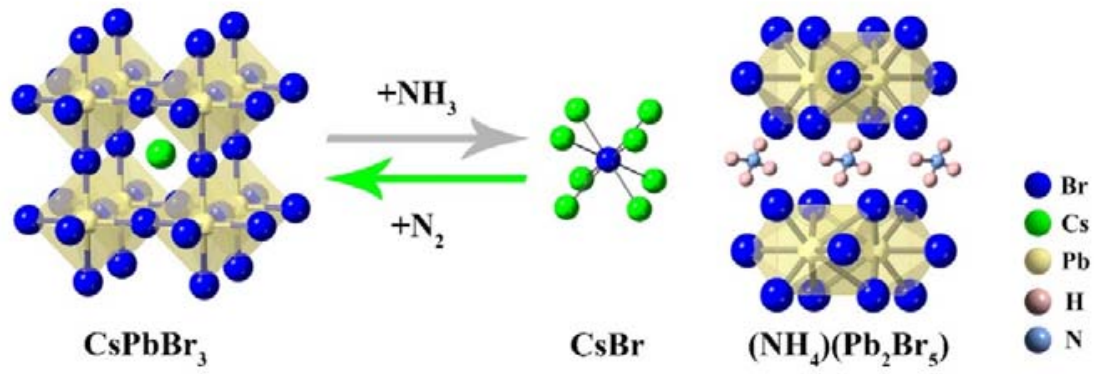

Figure S12 Schematic of the reversible transformation of $\mathrm{CsPbBr} 3$ into $\mathrm{CsBr}$ and $\left(\mathrm{NH}_{4}\right)\left(\mathrm{Pb}_{2} \mathrm{Br}_{5}\right)$.

(a)

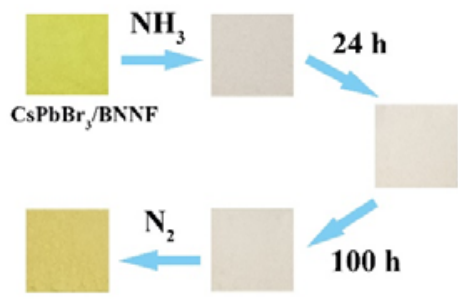

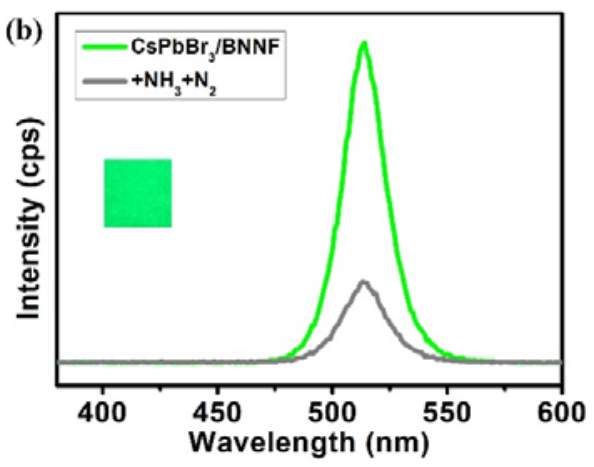

Figure $\mathrm{S13}$ (a) The color changes of $\mathrm{CsPbBr}_{3} / \mathrm{BNNF}$ composites under room light after exposure in $\mathrm{NH}_{3} / \mathrm{N}_{2}$ gas for $100 \mathrm{~h}$. After $24 \mathrm{~h}$ 's exposure in $\mathrm{NH}_{3}$, the powder remains white. Even the treating time lasts for up to $100 \mathrm{~h}$, the white color of powder still remains unchanged. After the long-time $\mathrm{NH}_{3}$ exposure, $\mathrm{N}_{2}$ was injected and the color of the sample changed back to yellow. (b) The emission spectra of $\mathrm{CsPbBr} 3 / \mathrm{BNNF}$ composite powders treated with $\mathrm{NH}_{3}$ gas for $100 \mathrm{~h}$ and then treated with $\mathrm{N}_{2}$ gas. The inset is photograph of $\mathrm{CsPbBr} / 3 / \mathrm{BNNF}$ composite powders after treated with $\mathrm{N}_{2}$ gas.

[1] V. K. Ravi, P. K. Santra, N. Joshi, J. Chugh, S. K. Singh, H. Rensmo, P. Ghosh and A. Nag, J. 
Phys. Chem. Lett., 2017, 8, 4988-4994. 